\title{
Influence of interpersonal relationships on acquaintance with digital technologies
}

\author{
Yulya Selezneva $^{1 *}$ and Victoria Pakhomova ${ }^{2}$ \\ ${ }^{1}$ Don State Technical University, Rostov-on-Don, 344010, Russia \\ ${ }^{2}$ Federal State Autonomous Educational Institution of Higher Education Crimean Federal University \\ named after V.I. Vernadskiy, Tavricheskaya Academy, Simferopol, Russia
}

\begin{abstract}
The article analyzes features of a modern family and shows the role of parent-child relations in the formation of the "I" image of a younger pupil; relationship between the peculiarities of parent-child relations and the degree of exposure of primary school children to the computer game reality is revealed. The thesis is substantiated that a certain type of upbringing, peculiarities of interaction with a child in a family provoke an excessive enthusiasm for computer games in children of primary school age, causing destructive changes in the construction of the "I" image of a younger pupil. The image of the "I" of active users of computer games is characterized by the indefiniteness of descriptions of the physical "I", weak reflection of their own emotional experiences and bodily sensations, unrealistic (overestimated) level claims, inadequate self-esteem. Childparent relations in families where active and inactive users of computer games are brought up differ in the types of parental attitudes: acceptance, authoritarian hypersocialization, infantilization and symbiosis.
\end{abstract}

\section{Introduction}

The modern world is characterized by the rapid development of computer and Internet technologies, which significantly change the entire mental and psychological structure of a person. The twentieth century is designated as informational, and the post prefix is assigned to the main terms of the century: posthistory, postmodernism, poststructuralism ( $\mathrm{J}$. Baudrillard, L.P. Grimak, V.A. Emelin, M. Castells, V.V. Savchuk, D.V. Truevtsev, M. Foucault, E.I. Khaibulina).[1] The beginning of the XXI century can no longer be unambiguously designated as the time after, and the society can no longer be called informational, comparing the first stages of the introduction and spread of the Internet and its current state, as well as the global coverage of the virtual space. New interpretations of understanding reality give rise to special conditions for a person's life, his selfdetermination: with the development of information technologies within communication networks, the term "virtual reality" has been firmly inscribed in human everyday life. (A.I. Voronov, A.E. Voiskunskiy, D.V. Ivanov, R.V. Mursalimov, I.A. Nikolaev, N.A. Nosov). [2]

We consider the concept of "virtual reality" as a reality in which the user has a certain

${ }^{*}$ Corresponding author: yulya.selezneva@gmail.com 
matrix outside his consciousness (in the form of a computer game), as well as options for manipulation within this given matrix, given by the game developer. At the same time, the user's representations, fantasy, and imagination are limited, outlined by the space of given options.

The focus of the main studies of this problem is aimed at studying the psychological mechanisms of involvement in virtual game reality of adolescents and adults (A.E. Voiskunskiy, A.M. Demilkhanova, M.S. Ivanov, L.O. Perezhogin, etc.).The researchers note that excessive passion for computer games can lead a user at any age to changes in the structure of the self-concept, emergence of additional forms of identification, when the character of the game becomes an image that distorts the identification process and has a negative impact on the formation of personality (A.M. Demilkhanova, A.E. Zhichkina).

Most researchers emphasize that in the post-information society the audience of users of the gaming virtual space is getting younger, and more and more researchers talk about the development trend of non-chemical computer addiction (T.Yu. Bolbot, V.A. Loskutova, A.V. Khudyakov, etc.) [3]. However, few of the modern researchers note that at present every second primary school pupil is an active user of various kinds of computer games. At primary school age, game plays a special role: with the help of game, the child brings closer to himself the meaning of many things that are not clear to him. Therefore, a computer game is considered as a phenomenon that provides the user with the opportunity to experience unlimited freedom, participate in various events, feel one's own success, removing any responsibility, and thereby contributing to the formation of inadequate selfesteem, as well as the constitution of a fantasy world of omnipotence (A.A. Avetisova, Yu. A. Brevnova, A.E. Voiskunskiy). It becomes obvious that with all the variety of research approaches, the role of computer games and virtual reality in the subculture of childhood remains insufficiently studied. The task arises to investigate the influence of virtual reality play on the formation of the image of the "I" of younger pupils, to determine the factors influencing the immersion of younger students in the world of virtual reality. Virtual game reality is one of the factors of constituting the image of the "I" of younger schoolchildren in those cases when the child delves into a computer game and identifies himself with virtual heroes.

Within the framework of this article, we present a fragment of a study related to assessing the impact of the characteristics of parent-child relationships on the immersion of primary school children in virtual computer reality. One of the hypotheses of our research was that the reason for the excessive enthusiasm of younger schoolchildren with computer games, followed by violations of identification, arises as a result of violations of parentchild relationships.

Speaking about the modern family, it should be noted that, according to a number of studies, today the most predominant type of family is "child-centric". Changes in social and cultural conditions naturally lead to a change in the types of communication and interaction in the family, a change in the main priorities in education, etc. The main characteristics of this type of family include bottom-up influence (all communication is subordinated to the interests and goals of the child); the type of interaction between an adult and a child unfolds as a "symbiosis"; in this connection, the risks of social adaptation for a child outside the family are increasing. As a consequence of the spread of the "child-centered" family in modern society, M. Harutyunyan highlighted the infantilism of young people and inability to self-determine themselves in the World. As noted above, the change in the family (in terms of its characteristics) is due to the influence of social and cultural factors. In particular, the reasons for the emergence of child centrism today are as follows: an increase in the life expectancy and coexistence of the child and parental generations; decrease in the number of children in the family; practical connections in joint work are replaced by emotional ones, and relationships are infantilized; the lack of clear norms for the 
authorization of relations between parents and children, which led to a violation of the distance between them; changes in the education system and the need for the presence of parents in the life of children under 17-22 years old. Thus, the acceptance of a particular role by parents in relation to children determines the style of upbringing, which in turn has far-reaching consequences and largely determines the process of a child's formation.

Currently, there are a lot of studies in science describing the influence of parent-child relations on the development of a child of primary school age. However, the problem of distortion of the image of the "I" of a younger pupil under the influence of immersion in the virtual world due to the violation of parent-child relations is not presented separately in science. In this connection, this study is of interest.

\section{Materials and methods}

Methods of psychological research: the author's questionnaire for diagnostics of computer games preferred by primary schoolchildren; methodology for determining the degree of enthusiasm for computer games by S.A. Kulakov; methodology "Ladder" by T.V. Dembo, S. Ya. Rubinstein (modified by S. G. Yakobson and V. G. Shchur); test "Who am I?" by M. Kuhn, T. McPartland (modified by T.V. Rumyantseva); projective drawing of a nonexistent animal. To describe the specifics of parent-child relationships in the families of younger schoolchildren - active and inactive users of computer games, the parental attitude questionnaire A.Ya. Vargi, V.V. Stolin and the Kinetic Figure of Seven. (KRS) by R. Bens and S. Kaufman.

The study involved 300 people - 215 children aged 6 to 10 years and 85 parents. Children aged 6 to 10; group of parents -40 men and 45 women, aged 25 to 52 years. The empirical tasks of the study included: identification and distribution of respondents of primary school age in accordance with the degree of their passion for computer games; study of the psychological characteristics of the "I" image of junior schoolchildren of active and inactive users of computer games; comparative analysis of parent-child relationships in the families of younger schoolchildren who are actively and inactively involved in computer games; identification of the factors that determine the process of constituting the image of "I" of junior schoolchildren in the field of gaming virtual reality.

\section{Results}

At the first stage of the study, an idea was drawn up about the regularity of visits and the time spent on computer games among senior schoolchildren, about the attitude towards computer games of schoolchildren's parents, a typology of computer games that are attractive to modern children of primary school age was compiled; the risk group for the development of computer gambling addiction among junior schoolchildren was determined. At the same time, it was important for us to make a distinction between the state of "predependence", or passion for a computer game and addiction. Based on the analysis of indicators of computer addiction (typology of M.S. Ivanov) and excessive enthusiasm for role-playing computer games (I.V. Kolotilova), ideas about chemical and non-chemical dependencies (A.Yu. Egorov; N.P. Zakharov; S.V. Krasnova), we have identified diagnostic criteria that make it possible to distinguish the state of pre-dependence in younger schoolchildren from the state of dependence. The state of pre-dependence differs from the dependence by the depth and level of expression of indicators. In case of preaddiction, the degree of addiction to computer games is defined as moderate or mild. In this case, the minimum frequency of circulation and the depth of the player's immersion in the game are observed; violations of social adaptation and changes in the physiological state 
are less total; there are no deep disturbances in appetite, sleep, signs of neurocirculatory dystonia and as the novegetative disorders; there are no deep individual mental disorders, but there is concern for the result of the game, the character; the player experiences a sense of unity with the hero of the game and the need to be similar to him; there may be difficulties with self-discipline, concentration.

Analysis of the attitude towards computer games among junior schoolchildren (S.A. Kulakov's methodology) made it possible to fix the prerequisites for the formation of addiction and distinguish two groups of junior schoolchildren based on differences in indicators such as emotional involvement, activity, regularity, duration of stay in the game; desire to be like the hero of the game; violation of self-control in game reality; changes in somatic health, manifested in headaches, etc. Thus, the group of younger schoolchildren overly keen on computer games was $(45 \%)$, and the group where the degree of passion for the virtual world of computer games can be considered acceptable (55\%). In order to assess the empirical validity, the Spearman rank correlation was calculated with respect to the selected groups - active and inactive users of computer games. Correlation analysis showed that in the group of junior schoolchildren that we identified - inactive users of computer games, the mean values have a greater scatter, no correlations were found between the significance of computer games and the parameters of gaming enthusiasm. Correlation at the level of significance $\mathrm{p} \leq 0.05$ was achieved in the group of active users according to the following scales: the significance of computer games in a child's life $(\mathrm{R}=0.51 ; \mathrm{p} \leq 0.05)$; the duration of the game (more than 1.5 hours per day) $(\mathrm{R}=0.66 ; \mathrm{p} \leq 0.05)$; pronounced enthusiasm for computer games $(\mathrm{R}=0.57 ; \mathrm{p} \leq 0.05)$, the presence of identification with a computer game character $(\mathrm{R}=0.59 ; \mathrm{p} \leq 0.05)$. A positive correlation indicates that as one indicator grows, another grows: an increase in the importance of computer games is directly proportional to an increase in all parameters (time spent at the computer, the number of preferred games, etc.).

Thus, the distribution of junior schoolchildren into groups of active and inactive users of computer games was based on the following criteria: presence of a different level of computer gaming enthusiasm for younger pupils, different objects for identification; severity of physical and psychological indicators.

At the next stage of the research, we were faced with the task of fixing the changes in the development of the self-image that arise under the influence of the immersion of primary schoolchildren in the computer game reality. We have identified the following differences in the construction of the image of the "I" of younger schoolchildren - active and inactive users of computer games: The image of the "I" of active users of computer games is characterized by the indefiniteness of descriptions of the physical "I", weak reflection of their own emotional experiences and bodily sensations, unrealistic (overestimated) level claims, inadequate self-esteem; The image of "I" of inactive users of computer games is more differentiated, positive, there is an optimal ratio of personal and social identities, implementation in the plane of relationships with the real, not the virtual world; users of role-playing computer games demonstrate specific features in self-presentation of the image of "I", expressed, in particular, in identification with the heroes of the game, while for users of non-role-playing computer games this kind of identification is not typical.

The hypothesis of our research was that one of the reasons for the active immersion of younger schoolchildren in the virtual world of computer games with subsequent identification disorders is the violation of parent-child relationships. According to psychoanalytic theories (M. Klein, J. Lacan, S. Freud), the acceptance of the subject's own "I" occurs due to the mechanism of projective identification $[4 ; 5 ; 6]$. In particular, S. Freud noted that identification is the initial form of emotional connection with significant others and the outside world in general. With inadequate relationships within the family, it is difficult for a child to find himself, his identity, and the loss of the object of identification 
threatens to lose the boundaries of his own "I". In the struggle with emptiness, a mechanism for searching for a virtual object of identification is launched into the structure of the child's "I" to preserve the imaginary integrity of the "I", an illusory identity. In addition, according to M.I. Lisina, the main factors influencing the formation of the "I" image include: the peculiarities of the child's perception by others; assessment of his achievements and failures; expectations related to implementation in society; the success of social relations and interactions; acceptance of their appearance, self-awareness of the somatic state [8]. Our assumption was based on the fact that in a situation of insufficient parental interest in the child and the level of intimacy, cooling of relations and contacts, the process of developing a positive self-attitude in a child may be complicated. Escape to the virtual world in this case can act as one of the possible ways to solve the situation, and thereby ensure a positive self-perception.

The empirical model and diagnostic map for the study of parent-child relationships in the families of younger schoolchildren was built as follows: we were studying relationship to family situations (Kinetic drawing of a family (KDF); and styles of child-parenting relationship (Parental attitude questionnaire (A.Ya. Varga and V.V. Stolin).

The results of comparing images of the family in groups of active and inactive users of computer games allow us to state the presence of the maximum severity of loneliness and difficulties communication: the drawings of active users of computer games are characterized by the distance of the figure of the father or mother from all family members (often children draw them with their backs, in the window, in car, etc.), single-figure family compositions $(\mathrm{p} \leq 0.01)$. The feeling of inferiority in the drawings among younger schoolchildren - active users of CG is found significantly more often than in the drawings of younger schoolchildren - inactive users of CG. At the same time, there is a lack of figures of real family members ( $18 \%$ to $3 \%, \mathrm{p} \leq 0.001)$.

The average values for KDF in both groups are clearly shown in Figure 1.

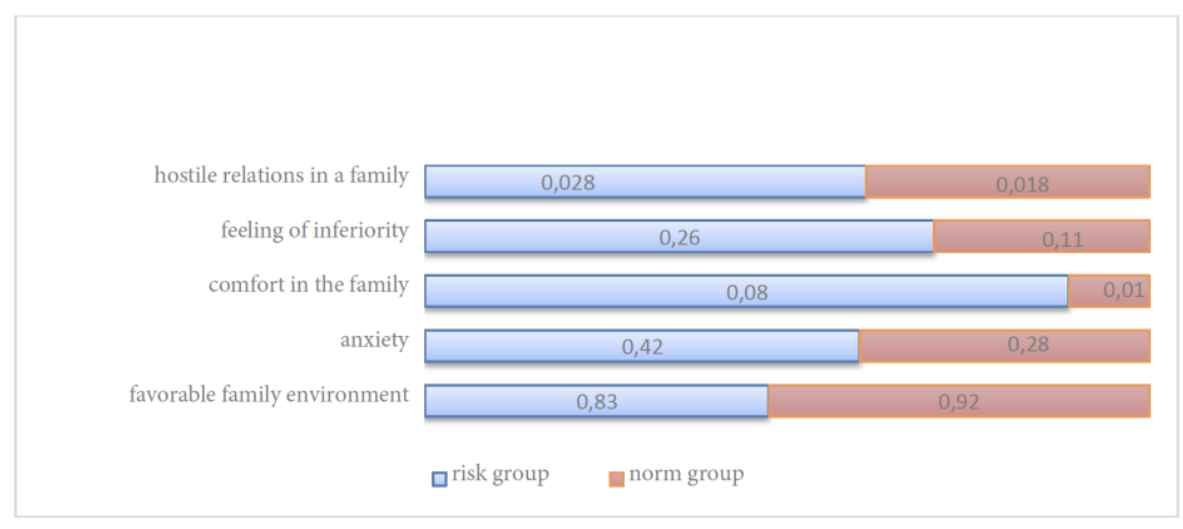

Fig. 1. Peculiarities of a family perception in two groups (in numerical values)

The results of statistical processing of the obtained data by the method of nonparametric statistics of the Mann-Whitney test showed no differences in all criteria, except for "feelings of inferiority: in the pictures of active users, signs of a feeling of inferiority were more often noted, compared with the pictures of inactive users $(U=2.78, p \leq 0.01)$.

An analysis of parental attitudes in the upbringing of active and inactive users is presented in Figure 2. 


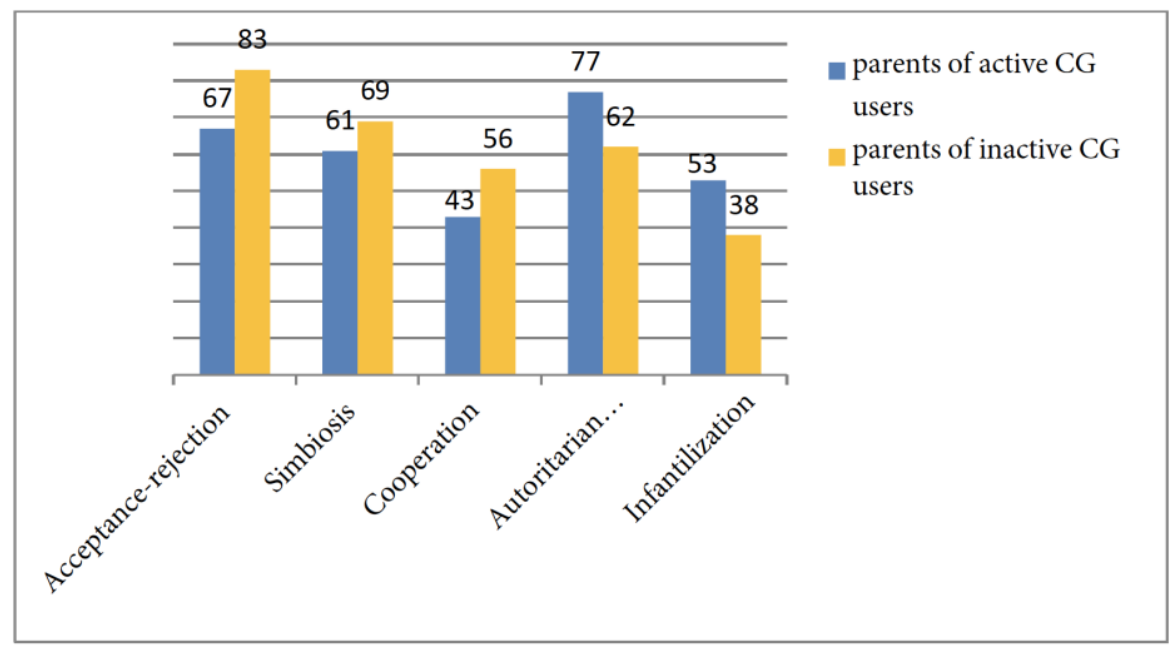

Fig. 2. Average values of indicators of parental attitude in the experimental and control groups (ORO test)

As Figure 2 shows, there are differences in parenting styles such as acceptance-rejection, symbiosis, authoritarian hyper-socialization, and infantilization. In particular, parents of active CG users are more likely to infantilize children $(\mathrm{p} \leq 0.01)$, are less focused on cooperation in communicating with children, compared with parents of younger schoolchildren inactive users $(\mathrm{p} \leq 0.01)$. Parents of active CG users more often than parents of inactive CG users have an authoritarian and symbiotic type of parental attitude ( $\mathrm{p} \leq$ 0.001). Thus, the parenting attitude in the control group of inactive CG users seems to be more harmonious due to the fact that it differs in a combination of pronounced acceptance (scale I) and willingness to cooperate with children (scale II).

\section{Discussion}

Correlation analysis made it possible to fix the following relationships:

- in families where the desire of parents to develop the activity of children, to establish cooperation with them is expressed, there is a weak degree of interest in computer games $(\mathrm{R}=-0.64 ; \mathrm{p} \leq 0.05)$. And, conversely, in families where parents pay little attention to emotional communication, children show more interest in computer games.

- Parents of younger schoolchildren who are active users of CG often resort to an authoritarian style of upbringing $(\mathrm{p} \leq 0.05)$. In contrast, parents of inactive users are more likely to demonstrate trust in their children by giving them the right to act independently.

- In a sample of schoolchildren - active users of computer games, direct correlations were found between the indicators of the projective methodology I am alone and Anxiety $(\mathrm{R}=0.52 ; \mathrm{p} \leq 0.01)$, I am alone and such a type of parental attitude as Authoritarian hypersocialization. $(\mathrm{R}=0.43 ; \mathrm{p} \leq 0.05)$, as well as with $\mathrm{I}$-virtual $(\mathrm{R}=0.51 ; \mathrm{p} \leq 0.01)$ and $\mathrm{I}$ ideal. $(\mathrm{R}=0.45 ; \mathrm{p} \leq 0.01)$. The revealed connections confirm the thesis about the existence of a relationship between the children's feeling of loneliness in the family, anxiety and an authoritarian type of parental attitude.

- Low self-esteem directly correlates with authoritarian hypersocialization $(\mathrm{R}=0.61 ; \mathrm{p} \leq$ $0.05)$, confirming the assumption that in families where the authoritarian type of upbringing prevails, the lack of openness and democracy in relationships among younger pupils is formed by low or inadequate self-esteem. 
- There are significant differences between the desire to achieve a symbiotic relationship with the child in mothers in both samples $(p \leq 0.05)$. Mothers of younger schoolchildren who are active users of computer games are more inclined to symbiosis than mothers of inactive users. Thus, K. Horney wrote that overprotection or self-sacrifice on the part of the "ideal" mother are the main factors that create the atmosphere that, more than anything else, lays the foundation for a feeling of tremendous insecurity in the future. [9] A. Adler described such a mother as a paralyzing independence. Relationships with a hyperprotective mother can lead to regression or stuck child at one of the stages of development, to the destruction and destabilization of the self-image, loss or blurring of the boundaries of his I. [10]

- Among younger schoolchildren who are inactive users, there is a correlation with a positive sign between cooperation and high self-esteem $(\mathrm{R}=0.56 ; \mathrm{p} \leq 0.01)$. Such correlations make it possible to judge the existence of a relationship between the desire of parents to establish partnerships with children and a proportional increase in positive selfacceptance among younger schoolchildren.

Nowadays there is a scientific research revealing the effect of child-parenting relationships on computer addiction in children. So, Lieberoth A., Fiskaali A. have published the results of the research in article «Can Worried Parents Predict Effects of Video Games on Their Children? A Case-Control Study of Cognitive Abilities, Addiction Indicators and Wellbeing». This research showed that parents' concerning about children's obssesive gaming relates to the increase of children's anxiety and Exposure of children to Virtual Computer Reality. "A finding that warrants deeper scrutiny is the correlation between parental worry and gaming addiction indicators related to conflicts with others over gaming and others trying to limit your game time". And also «in-depth studies of family experiences, conflicts, stressors, and negotiations about proper game time couldbe a key to understanding this paradox in depth, andperhaps to determine the appropriateness of scale items relatedto family conflict as diagnostic criteria for an addictivedisorder in children». [11]

Weisel A. studied the ramifications of excessive use of media on personality development, the development of symbolic and thinking functions and on psychic reality. The question whether a computer game can mobilize or destroy something in the inner world of a child is discussed. The researchers are convinced that a children's choise of a computer game is not accidental. Computer gamers use their game to activate the field of a personal psychic reality. However, the traumes reproduced in the game but not resolved stay in real life. [12]

\section{Conclusions}

In conclusion, it is necessary to mention that rules of how a virtual reality impacts on person is an important field of psychological researches. The changing of self-assessment and behavior, cognitive biases caused by the child's exposure to the virtual reality mainstream the issues of the analysis of the factors, which influence on the active engagement in the virtual reality. Our research proofs the fact that one of the reasons of primary schoolchildren' high interest in computer games is based on the disruption in parent-child relationships. Thus, the active exposure of younger schoolchildren to the virtual world of computer games with subsequent violations of identification may occur due to violations in child-parent relationships, expressed in superficial emotional contact between parents and children, the predominance of parental authoritarian hypercontrol, the desire to establish a symbiotic relationship and infantilization of children. The virtual reality becomes a screen with help of which a child can escape from family problems and hide from anxiety and loneliness, compensating for the difficulties and failures. Thus, the 
informational world, in spite of the many aspects of positive influence is still a menace to the mental development of a child.

\section{References}

1. J. Baudrillard, Émile Michel Sioran: Matrix of Apkalypsis. Last sunset of Europe (Algorithm, Moscow, 2015).

2. V.Nicolaev, Virtuality as a natural scientific, technical and cultural phenomenon (Saratov, 2004).

3. A.V. Khudyakov, A.V. Ursu, A.M. Starchenkova, Medical psychology in Russia: electron. scientific. Magazine 4(33), 1-10 (2015).

4. M. Klein, Psychoanalytic works (In the VII volume, ID. ERGO, 2007).

5. J.Ya. Lacan, in Freud's theory and in the technique of psychoanalysis (Publishing house, Gnosis, Logos, Moscow 1999).

6. Z. Freud, Reader: in 3v. Volume 1: Basic concepts, theories and methods of psychoanalysis (Kogito - Center, Moscow, 2016).

7. D.V. Winnicott, Little children and their mothers Class (Moscow, 2011).

8. M.I. Lisina, Problems of ontogenesis of communication (SPb, Piter, 2009).

9. K. Horney, Our internal conflicts. The constructive theory of neurosis (Piter, Masters of Psychology, SPb, 2019)

10. A. Adler, Practice and theory of individual psychology (Publishing house of the Academic project, Moscow, 2015)

11. A.Lieberoth, A.Fiskaali, Addiction Indicators and Wellbeing, Frontiers in Psychology 11, 1-18 (2021).

12. A.Weisel, Journal of Analytical Psychology 60 (2), 198-219 (2015). doi.org/10.1111/1468-5922.12144

13. Yu.P. Zinchenko, World of psychology 1 (73), 31-42 (2013).

14. S.N. Sidorova, V.S. Elchaninov, N.K. Gabdulkhakova, Young Scientist 7, 294-296 (2014).

15. Exploring AR and VR's Potential, Education and Changing Human Behavior With Virtual Experiences, Electronic resource, July 18. (2014) http://www.roadtovr.com/exploring-ar-vrs-potential-education-changinghumanbehavior-virtual-experiences/

16. M.D. Griffiths, Med. psihol. Ross. 4 (33), 1-13 (2015).

17. C.-T. Sun, H. Lin, H.H. Tinn, Cyberpsychol Behav 9(5), 560-570 (2006). 